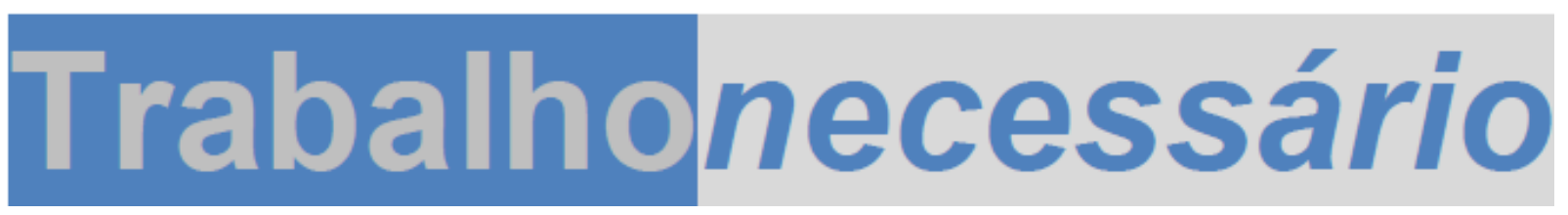

\author{
Issn: 1808 - 799X \\ ano 11, no $16-2013$
}

\title{
O ENSINO PROFISSIONAL NO BRASIL: ATENDER “OS POBRES E DESVALIDOS DA SORTE" E INCLUÍ-LOS NA SOCIEDADE DE CLASSES - UMA IDEOLOGIA QUE PERPASSA OS SÉCULOS XX E XXI
}

\author{
Luiz Alberto Azevedo ${ }^{1}$ \\ Marival Coan ${ }^{2}$
}

\begin{abstract}
Resumo: Neste texto elabora-se um resgate acerca da origem da educação e a sua relação com a educação profissional, relativa à construção do ser humano e segundo uma intencionalidade que remete à instituição caracterizada por uma dualidade educacional pelo fato de estar inserida numa sociedade de classes. Desenvolve-se um resgate histórico sobre a ação normativa de conselheiros do Conselho Nacional de Educação sobre a educação profissional, que a estratifica com vistas a atender determinados interesses de determinados segmentos sociais. Apresenta-se, ainda, uma reflexão sobre os encantos e desenganos promovidos pela ação de vários sujeitos sociais, com vistas a manter a educação profissional e tecnológica numa perspectiva redentora, incutindo a ilusão de que o Estado brasileiro age a fim de superar a lógica desumanizadora do capital.
\end{abstract}

Palavras-chave: Educação, Educação profissional, Trabalho e inclusão.

\begin{abstract}
This essay elaborates a recovery on the origin of education and its relationship with professional education, regarding the construction of the human being and according to an intentionality that refers to the institution characterized by an educational duality given it is inserted in a society of classes. A historical recovery is developed on the normative action by counselors of the Education National Council on professional education, which stratifies aiming at meeting certain interests of certain social segments. A reflection on the charms and deceives promoted by the action of several social subjects in view the

\footnotetext{
1 Engenheiro, Doutor em Educação pelo PPGE/UFSC. Professor efetivo do IF-SC. Pesquisador do Gepeto/UFSC e NUPED/IFSC.e-mail: lazevedo@ifsc.edu.br.

${ }^{2}$ Licenciado em Filosofia, mestre e doutor em Educação pelo PPGE/UFSC. Professor efetivo do IFSC. Pesquisador do Gepeto/UFSC e NUPED/IFSC.E-mail: marival@ifsc.edu.br
}

TrabalhoNecessário - www.uff.br/trabalhonecessario; Ano 11, № 16/2013. 


\section{Trabalhonecessário}

Issn: 1808 - 799X

ano $11, \mathrm{n}=16-2013$

maintenance of professional and technological education as a redeeming perspective, instilling the illusion that the Brazilian State acts in order to overcome the dehumanizing capital logic is also presented.

Key words: Education, Professional education, Work and inclusion.

\section{A EDUCAÇÃO E O ENSINO PROFISSIONAL NO BRASIL}

Entende-se que o processo histórico da educação formal no Brasil se encontra intrinsecamente relacionada ao grau de desenvolvimento econômico, político e social da nação brasileira e que ao longo da sua formação histórica a educação sempre foi apresentada como caminho para a civilização, para a modernidade, para um futuro melhor para todos, embora, na prática, as ações políticas não correspondam a esse desejo. Diferente disso, ao longo da história brasileira se percebe que para os diversos grupos dominantes o mais importante sempre foi uma educação com dupla finalidade. Uma destinada a preparar as elites políticas e quadros profissionais de nível superior em estreita consonância com a ideologia política e social para garantir a construção e a manutenção da ordem, a estabilidade das instituições e a preservação do regime hierarquizado em classes e outra de caráter mais pragmático para atender as demandas do mercado e do mundo da produção.

Para discutir o tema também se considera importante apresentar a compreensão de que a educação no Brasil foi e continua sendo vista como uma ação sistemática decorrente de uma equação em que participam a instituição escolar com seu corpo diretivo e pedagógico, o professor com seus objetivos e metodologia delineada e que, muitas vezes é visto como o detentor do conhecimento, os objetos de aprendizagem, como livros, que são formalmente 


\section{Trabalhonecessário}

Issn: 1808 - 799X

ano 11, no $16-2013$

concebidos e portadores de uma determinada concepção de mundo e de conhecimento destinados a dar sustentação ao desenvolvimento de processos de ensino e de aprendizagem. Também participam outros sujeitos da sociedade constituída, os quais se colocam no contexto como interlocutores e mediadores. Trata-se de uma ação de profissionais vinculados a uma determinada institucionalidade e com objetivos que podem confrontar-se com outros objetivos de uma esfera superior aos da esfera operacional, bem como, com aqueles decorrentes de políticas estabelecidas numa outra esfera, seja ela: municipal, estadual ou federal, os quais tendem a ser conformados, em instâncias diversas, por sujeitos externos de outra esfera social, como a dos segmentos econômicos e produtivos, mediante o estabelecimento de uma correlação de forças. ${ }^{3}$

No que tange à organização do sistema brasileiro de educação o assunto não é menos importante porque, segundo a norma legal advinda da Lei de Diretrizes e Bases da Educação Nacional (LDBEN), Lei $n^{\circ}$ 9.394/1996, em seu artigo $8^{\circ}$ estabelece que a União, os Estados e os Municípios, assim como o Distrito Federal, incumbir-se-ão de organizar e estruturar os seus "Sistemas de Ensino", assim como são responsáveis pelas suas instituições, inclusive definindo normas complementares, tudo, porém, em regime de colaboração. Em 30 de agosto de 2004 o Instituto Brasileiro de Geografia e Estatística (IBGE) comunicou que o Brasil tinha 5.560 municípios; somando-se este quantitativo com os 26 estados da federação e o Distrito Federal, ter-se-á um total de 5.587 "Sistemas Educacionais", caracterizando uma autêntica "Torre de Babel", porém perpassados por um objetivo comum: "fazer educação".

O próprio termo "educação" é polissêmico e depende muito da apropriação que o indivíduo e grupos podem fazer do mesmo. Nesse caso, pode

\footnotetext{
${ }^{3}$ Nosella (2005, p. 230) destaca que a política vista a partir da ótica dos meios "é essencialmente poder ou domínio" e que, em se tratando de poder, pode caracterizar-se como poder econômico, ideológico e político, cuja conceituação dos mesmos pode ser verificada no texto do autor. Sem ter a pretensão de problematizar, interpreta-se que a política está indissociada da busca pelo poder, constituindo-se, portanto, como um instrumento do ser humano.
} 


\section{Trabalhonecessário}

Issn: 1808 - 799X

ano 11, no $16-2013$

assumir um caráter marcantemente político de acordo com a posição que o indivíduo ou grupo ocupa na sociedade, e, segundo a sua visão sobre o que significa educação e ato educativo, considerando o conceito que imprime na palavra educação em relação a sua intenção, com vistas a the dar uma determinada intencionalidade, um objetivo específico, que pode estar subjacente escamoteando o seu verdadeiro propósito ${ }^{4}$. Há de se destacar também que a educação está institucionalizada por dentro de uma sociedade de classes que se vincula diretamente ao aprofundamento da divisão do trabalho e de sua especialização, pressionando segmentos desta mesma sociedade para dividi-la segundo propósitos, contudo, a partir de um modelo de sociedade contratual (SAVIANI, 2007) que se transforma e se realimenta desta mesma transformação.

Partimos da premissa de que a educação é uma prática do homem que ao educar-se, educa a si e aos seus, configurando-se como um processo histórico-ontológico porque é desenvolvida pelo ser humano no transcorrer de uma temporalidade histórica, e o seu resultado se materializa na constituição e conformação do próprio ser humano (SAVIANI, 2007).

Nessa constituição histórica do ser humano, trabalho e educação se articulam. Conforme compreende Vieira Pinto (2005, p. 37), o homem está destinado a viver na natureza, porém "apenas, o que se entende por 'natureza' em cada fase histórica corresponde a uma realidade diferente", justamente por essa inserção a atuação do homem pelo trabalho e pela técnica diferente em cada momento.

Essa nova condição do homem hodierno nos faz pensar acerca do que se poderia entender por "trabalho material" e trabalho não-material" (SAVIANI, 1997), face à condição a que chegou o ser humano no contexto atual considerando o

\footnotetext{
${ }^{4}$ Para substanciar este entendimento apropria-se da seguinte manifestação de Frigotto, Ciavatta e Ramos (2005, p. 8): "Acordos assinados pelo governo brasileiro com a USAID (United States Aid International Development) demonstravam a intenção de se ampliar ao máximo as matrículas nos cursos técnicos e de promover uma formação de mão de obra acelerada e nos moldes exigidos pela divisão internacional do trabalho."
}

TrabalhoNecessário - www.uff.br/trabalhonecessario; Ano 11, № 16/2013. 


\section{Trabalhonecessário}

Issn: 1808 - 799X

ano 11, no $16-2013$

desenvolvimento de sua intelectualidade, bem como dos meios necessários a sua vivência, ou seja, a construção de um mundo tecnológico a partir da conformação da Natureza aos seus objetivos mediante o desenvolvimento de uma ação intencional, suportada no desenvolvimento e na conformação do trabalho, no transcorrer de sua historicidade, face à condição à qual o ser humano se projeta $\mathrm{e}$ é projetado. Sobre esta distinção entre trabalhos, também apresentadas como "trabalho superior e simples ou mesmo entre "trabalho qualificado e nãoqualificado", Marx (2008, p. 231) esclarece que, em parte, decorrem "de meras ilusões, ou pelo menos de distinções que cessaram de ser reais, mas sobrevivem convencionalmente, por tradição".

Os contornos desta nova temporalidade instituída por este mesmo ser humano, que agora tem como elementos primários não mais a natureza dada, mas uma natureza que é produto da realização do seu sistema nervoso, decorrente significativamente de um "trabalho não-material" que se verticaliza no conhecimento historicamente produzido por este mesmo ser em que se situa a educação, deslegitima a visão tradicional de que a educação se resumiria a processos de ensino. Há de se considerar que o ensino, por conseguinte, integra a educação e que o ato educativo é muito mais do que apenas processos de ensino e de aprendizagem porque este está vinculado, cada vez mais, aos contornos do "trabalho não-material" que, na visão de Saviani (1997, p. 17), "tem a ver com ideias, conceitos, valores, símbolos, hábitos, atitudes, habilidades".

O trabalho educativo, portanto, constitui-se a partir de uma intencionalidade com vistas a produzir, "em cada indivíduo singular, a humanidade que é produzida histórica e coletivamente pelo conjunto dos homens". (SAVIANI, 1997, p. 17). Este trabalho educativo, que se institui como uma prática humana direcionada, na compreensão de Luckesi pode ocorrer a partir de três tendências filosófico-políticas, denominadas de: "educação como redenção; educação como reprodução; e educação como um meio de 


\section{Trabalhonecessário}

Issn: 1808 - 799X

ano 11, no $16-2013$

transformação da sociedade". (LUCKESI, 1990, p. 37). Avalia-se pertinente esclarecer, mesmo não se tendo a prerrogativa de discutir cada uma destas tendências, que o autor entende que é "filosófica" porque está relacionado com um sentido e é "política" porque se dirige a um fim específico que para atingi-lo se faz necessário viabilizar ações.

A partir dessa abordagem inicial sobre determinada compreensão de educação e sua articulação com o mundo concreto do trabalho e da técnica, se constrói uma intersecção com a educação profissional no Brasil, resgatando que a sua origem está discutida em literatura especializada como a trabalhada por Luiz Antonio Cunha em suas três obras: "O ensino de ofícios artesanais e manufatureiros no Brasil escravocrata"; "O ensino de ofícios nos primórdios da industrialização"; e "O ensino profissional na irradiação do industrialismo". Uma leitura dessa tríade possibilita verificar que o autor desenvolve um trabalho a partir de uma perspectiva histórica, delineando como foi conformando-se a construção de uma dualidade entre um tipo de ensino profissional dirigido para profissões labutadoras e a educação propedêutica destinada a um estrato social hegemônico. Nessas obras o autor, em sua exposição, apresenta como foi ocorrendo a passagem de uma educação profissional artesanal para manufatureira e, posteriormente, industrial, segundo os condicionantes políticos e sociais de cada época, todavia, sempre direcionada para "os desvalidos da sorte"; a partir dos quais é possível verificar os vínculos entre educação e trabalho, porém numa visão de mercadoria.

Frigotto, Ciavatta, e Ramos (2005) destacam que essa dualidade no Brasil é fruto de séculos de escravismos em que perdurou uma situação de uma minoria definindo o tipo de educação que deveria ser direcionada a uma grande maioria: preparação para o trabalho manual, com vistas a treinar braços e desenvolver músculos, enquanto a outra era organizada para aguçar os olhos e desenvolver o intelecto. Esse dualismo educacional no Brasil não foi superado 


\section{Trabalhonecessário}

Issn: 1808 - 799X

ano 11, no $16-2013$

nem com a passagem para o século $X X I$ em que a produção organizada, em nome da competitividade, acelera uma incorporação crescente por ciência e tecnologia aos seus processos, tampouco com os governos "ditos" democráticos, como era de se esperar, face às promessas hipotecadas para a construção de outra sociabilidade, assim como, retroagiu, acentuando-se a visão mecanicista da educação profissional a um fim que inclusive diverge da manifestação contemporânea dos detentores do capital: a formação de uma força de trabalho de qualidade.

Corroborando com essa análise crítica, Kuenzer, analisando a educação profissional no ano 2000, entende que continua em curso a precarização da educação profissional com vistas a legitimar a formação de uma força de trabalho para ser inserida em trabalhos precarizados, em seu entendimento, "por meio da formação de subjetividades flexíveis, polivalentes e empreendedoras". A autora compreende que:

[...] Na sociedade capitalista, na qual se produzem relações sociais e produtivas que têm a finalidade precípua de valorização do capital, não há inclusão que não atenda a esta lógica, como não há possibilidade de existência de práticas pedagógicas autônomas; apenas contraditórias, cuja direção depende das opções políticas que definem os projetos, seus financiamentos e suas formas de gestão. (KUENZER, 2006, p. 907).

Analisando a história da educação profissional no Brasil, Não resta dúvida de que, independentemente da força impositiva da norma legal dirigida à essa modalidade de educação e considerando suas brechas e as mediações travadas, decorrentes dos processos de reformas dirigidas a esse fazer educacional, a Rede Federal de Educação Tecnológica, não obstante, vivenciou experiências diferenciadas que contribuíram para uma reflexão mais crítica sobre esse tipo de ensino. Lima Filho (2005, p. 358) destaca que tais medidas são "fruto das ações dos sujeitos sociais $e$ interesses que se manifestam internamente $e$ 


\section{Trabalhonecessário}

Issn: $1808-799 X$

ano 11, no $16-2013$

externamente, na comunidade educacional e na sociedade civil". Tais efeitos sobre as Instituições Federais de Educação Tecnológica (IFETs) têm como resultado, por exemplo, o abandono dos cursos integrados em favor das modalidades concomitante ou subsequente, com vistas a uma oferta de cursos técnicos pós-médios e de cursos superiores de tecnologia (CSTs).

De uma forma geral os quatro anos do governo de Itamar Franco (19921995), os oito anos do governo Fernando Henrique Cardoso (FHC) (1995-2003) e os oito anos do Luiz Inácio Lula da Silva (2003-2011), totalizando 20 anos de governo, mantendo suas respectivas diferenças de caráter micro, resumiram-se a instituir políticas reformistas que aprofundaram a dualidade educacional brasileira, além de deteriorar e precarizar tanto uma como outra, assim como aprofundar a sua condição de mercadoria. A situação educacional no Brasil está afunilada, ou seja, algumas poucas instituições educacionais têm desenvolvido a sua prática educacional a partir da sua visão de ato educativo em sentido mais amplo com perspectivas emancipatórias, enquanto que o governo atual de Dilma Rousseff contribui com uma política reesquentada ${ }^{5}$ denominada de Programa Nacional de Acesso ao Ensino Técnico e Emprego (PRONATEC) ${ }^{6}$, com o objetivo de criar uma força de trabalho ainda mais aligeirada e precária porque se dá mediante processos frágeis, face à urgência que impõe, a qual contribuirá ainda mais para

\footnotetext{
${ }^{5}$ O governo José Sarney (BRASIL, 1990, p. 14), em seu documento: "Realizações do Ministério da Educação - Período: 1985/1990", comunica, em 1987, que foi dada ênfase ao Programa de Expansão e Melhoria do Ensino Técnico (PROTEC), mediante "a criação 66,3 mil novas vagas, decorrentes de recuperação e ampliação de unidades escolares já existentes", o qual foi, posteriormente, encampado pelo governo Itamar Franco, em 1993, com uma verba de Cr\$ 5 trilhões.

${ }^{6}$ O MEC divulga em seu website (2012) que o PRONATEC "tem como objetivo principal expandir, interiorizar e democratizar a oferta de cursos de Educação Profissional e Tecnológica (EPT) para a população brasileira. Para tanto, prevê uma série de subprogramas, projetos e ações de assistência técnica e financeira que juntos oferecerão oito milhões de vagas a brasileiros de diferentes perfis nos próximos quatro anos", sendo colocado como elemento inovador deste programa "a criação da Bolsa-formação, que permitirá a oferta de vagas em cursos técnicos e de formação inicial e continuada (FIC), também conhecidos como cursos de qualificação".
} 


\section{Trabalhonecessário}

Issn: 1808 - 799X

ano 11, no $16-2013$

a desindustrialização ${ }^{7}$ brasileira. Trata-se de uma política que chancela a educação profissional como um ensino mecanicista e dirigido, agora, para os "excluídos do consumismo", de forma a assegurar-lhes uma determinada condição ao consumo da materialidade processada, um tipo de "inclusão social" que não Ihes possibilita a superação da condição cultural na qual se encontram.

\section{A AÇÃO DO CONSELHO NACIONAL DE EDUCAÇÃO SOBRE A EDUCAÇÃO PROFISSIONAL}

A partir desta ótica apresentada por Saviani (1997) sobre o trabalho educativo e a compreensão de Luckesi (1990), assim como o contexto de tensionamento da educação profissional pública via PRONATEC, avalia-se relevante para o propósito do texto resgatar que no Parecer do Conselho Nacional de Educação (CNE)/Câmara de Educação Básica (CEB) $n^{\circ}$ 5, de 1997, os conselheiros $^{8}$ enaltecem a sua importância, ao se referirem sobre o seu compromisso com a estrutura educacional da União elaborando normatizações e realizando a supervisão, de acordo com o que está estabelecido no parágrafo $1^{\circ}$ do artigo 9, da Lei $n^{\circ}$ 9.394, de 20 de dezembro de 1996, a Lei de Diretrizes e Bases da Educação Nacional (LDBEN). Entende-se que esta questão é de centralidade ímpar para a educação brasileira a fim de definir prerrogativas relativas à mobilidade do CNE para além da constituição de agente produtor de normatizações a serviço de integrantes ou simpatizantes de partidos políticos que

\footnotetext{
7 O Departamento Intersindical de Estatística e Estudos Socioeconômicos (DIEESE, 2011, p. 2) apresenta este conceito como "um processo que provoca a reversão do crescimento e da participação da indústria na produção e na geração de empregos".

${ }^{8} \mathrm{Na}$ Lei $n^{\circ} 9.131 / 1995$ está posto que os conselheiros do CNE "exercem função de interesse público relevante, com procedência sobre quaisquer outros cargos públicos de que sejam titulares", competindo-Ihes "subsidiar a elaboração e acompanhar a execução do Plano Nacional de Educação".
} 


\section{Trabalhonecessário}

Issn: $1808-799 X$

ano $11, \mathrm{n}=16-2013$

assumem cargos da estrutura do Estado brasileiro, como do Ministério da Educação (MEC).

No item 3.6 do Parecer CNE/CEB $n^{0}$ 5/1997 conselheiros do CNE se limitam a informar sua compreensão sobre a educação profissional, constituída como modalidade de ensino vinculada à educação básica e à educação superior, inclusive admitindo-a com vistas a propiciar habilitação profissional, com a possibilidade de ser desenvolvida em instituições de ensino médio ou em instituições especializadas de educação profissional, reconhecendo que compete ao "Ministério da Educação e do Desporto, ouvido o Conselho Nacional de Educação," estabelecer diretrizes curriculares nacionais para a mesma, declinando de sua competência política como órgão estratégico do Estado brasileiro. Convém também destacar que conselheiros do CNE, nesse item, acolhem e aceitam o fato do governo FHC ter, mediante dispositivos normativos, regulamentado a educação profissional referida nos artigos 39 a 42 da LDBEN/1996, como foi o caso do Decreto $n^{\circ}$ 2.208/1997.

Em 3 de dezembro de 1997, no Parecer CNE/CEB n ${ }^{\circ}$ 17/1997, conselheiros do CNE se apropriam do Decreto $n^{0} 2.208 / 1997$ do governo FHC, uma norma legal elaborada em gabinete e com viés ideológico de partido político, para definir diretrizes curriculares nacionais para a educação profissional de nível médio, ou seja, para a formação de técnicos de nível médio, tendo como objetivo a formação de uma força de trabalho direcionada à "vida produtiva", face às necessidades apresentadas pelo mercado de trabalho, assumindo a postura de correia de transmissão da intencionalidade advogada pelo governo e do próprio mercado. Neste sentido, conselheiros fazem referência à certificação de competências como instrumento destinado a antecipar essa formação profissional, mediante processos de formação inicial e continuada, assim como de 


\section{Trabalhonecessário}

Issn: $1808-799 X$

ano 11, no $16-2013$

qualificação e requalificação profissional, tudo, porém vinculado aos novos perfis profissionais que os agentes econômicos e sociais estavam a demandar ${ }^{9}$.

$\mathrm{Na}$ manifestação de conselheiros do CNE no Parecer CNE/CEB $n^{\circ}$ 17/1997 despontam termos como: desvinculação, flexibilização, habilitação e terminalidade, a fim de compreenderem que "o chamado currículo integrado é extremamente difícil de ser modificado e por isso mesmo acaba se distanciando cada vez mais da realidade do mundo do trabalho" (Brasil, 1997 b, p. 5) e distante de uma necessidade social que estes não esclarecem, por conseguinte, colocamna como uma oportunidade de trabalho, limitando-se a regulamentar uma operacionalização mecanicista e sintonizada com as novas diretrizes econômicas. Julga-se oportuno deixar evidenciada a compreensão de que os cursos técnicos de nível médio, no caso do Instituto Federal de Santa Catarina (IFSC) que integra a Rede Federal de Educação Profissional, Científica e Tecnológica, não são integrados, mas justapostos numa sequência combinada de disciplinas ${ }^{10}$, e que conselheiros veem essa flexibilização como um descolamento do ensino médio e organização modular para dar mobilidade à certificação de competências, oportunizando, assim, ao aluno, mesmo ainda não tendo concluído o curso, o ingresso imediato ao mercado de trabalho porque ele já dispõe de habilidades e competências.

Assim, em 2 de abril de 2001, ainda governo FHC, o CNE publica o Parecer CNE/Câmara de Educação Superior (CES) n 436 que aborda os Cursos Superiores de Tecnologia (CSTs), ou seja, a formação de tecnólogos, padronizando, de acordo com a área profissional, as cargas horárias mínimas de

\footnotetext{
${ }^{9}$ Avalia-se que essa temática é abordada por Ramos (2002), em "A educação profissional pela pedagogia das competências e a sua superfície dos documentos oficiais".

${ }^{10} \mathrm{Em}$ fevereiro de 2012 a direção do campus Florianópolis do IFSC realizou um debate sobre questões pedagógicas, em cuja oportunidade, verificou-se que professores da área de formação geral compreendem a sua participação nos ditos cursos técnicos integrados como prestação de um serviço aos departamentos acadêmicos técnicos, em virtude de esses não se configurarem cursos integrados.
} 


\section{Trabalhonecessário}

Issn: $1808-799 X$

ano 11, no $16-2013$

2.400, 2.000 e 1.600 horas. ${ }^{11}$ Neste Parecer conselheiros do CNE justificam a sua ação em virtude de que tradicionalmente a sociedade brasileira não vinha dando a devida importância para a educação que preparava trabalhadores, porque esta se limitava, até a década de 1980, ao treinamento devido à forma como estava organizado o mundo do trabalho que passou a agregar um arcabouço de tecnologias complexas. Desta forma, esse novo cenário econômico e produtivo, na compreensão de conselheiros do CNE, demandava uma sólida base de educação geral com vistas à preparação de uma força para o mundo do trabalho, além da formação polivalente que possibilitasse o domínio operacional de um determinado fazer, bem como "a compreensão global do processo produtivo, com a apreensão do saber tecnológico, a valorização da cultura do trabalho e a mobilização dos valores necessários à tomada de decisões" (Brasil, 2001, p. 2), tudo isto numa perspectiva de cursos estruturados a partir de uma formação mínima de dois a três anos e entendidos como de nível superior.

Fundamentados numa visão discursiva de que seria possível agir no sentido de superar o enfoque tradicional da educação profissional com vistas à formação de profissionais para além da ótica mercadológica, conselheiros do CNE delinearam como deveria dar-se essa formação e qual seria o tipo de instituição educacional que a promoveria, mediante a apropriação de uma série de normas legais produzidas pelo estafe governamental de vários governos, de forma a potencializar esta ação. O que se evidencia, contudo, é a instituição de uma incumbência acrítica para esse tipo de educação a ser efetivada por professores, uma espécie de autoajuda, sem que seja abordado por conselheiros pressupostos pedagógico e práticas educativas.

\footnotetext{
${ }^{11} \mathrm{O}$ artigo segundo do "Acordo de Admissão de Títulos e Graus Universitários para o exercício de atividades acadêmicas nos Estados partes do Mercosul" (BRASIL, 2003), assinado entre os países da América Latina: República da Argentina, República Federativa do Brasil, República do Paraguai e República Oriental do Uruguai, em março de 1991 e oficializado como Decreto Legislativo $n^{\circ} 800 / 2003$, considera títulos de graduação "aqueles obtidos em cursos com duração mínima de quatro anos e duas mil e setecentas horas cursadas".
} 


\section{Trabalhonecessário}

Issn: $1808-799 X$

ano $11, \mathrm{n}=16-2013$

Outra contradição está, por conseguinte, no fato de conselheiros do CNE afirmarem no Parecer CNE/CEB n ${ }^{0}$ 17/1997 que a educação profissional dirigida à formação de tecnólogos "integra-se à educação superior e regula-se pela legislação referente a esse nível de ensino" (Brasil, 1997 b, p. 6), entretanto, já haviam imposto uma camisa de força em suas cargas horárias, as quais não possibilitam uma formação de semelhante densidade dos cursos de graduação que têm em suas matrizes curriculares a presença de uma densidade em ciência e tecnologia, mantendo uma preparação estritamente alinhada a um determinado posto de trabalho.

Verifica-se que conselheiros do CNE no Parecer da CNE/CES $n^{\circ}$ 436/2001 não abordam a questão da modalidade educação tecnológica como sendo o tipo de educação a partir da qual ocorreria a formação de tecnólogos, limitando-se a vincularem esta formação com os Centros Federais de Educação Tecnológica (CEFETs), inclusive declarando que a instituição do Sistema de Ensino Nacional de Educação Tecnológica prospectada pelo governo Itamar, mediante a Lei $n^{\circ}$ 9.394/1996 que foi revogada pelo governo FHC, "tem sido feita por variada hierarquia de Leis, Decretos e Portarias Ministeriais" (Brasil, 2001, p. 2), configurando um autêntico simulacro. Nas questões relativas à estruturação curricular dos CSTs, conselheiros, assim como fizeram no Parecer CNE/CEB $n^{\circ}$ 17/1997, abordam a interdisciplinaridade animus rem sibi habendi sem que apresentem a sua compreensão epistemológica a respeito de um possível vínculo com o tema que discorrem, vulgarizando o seu uso.

Em seguida, 3 de dezembro de 2001, já no final do governo FHC, o MEC se movimenta junto a conselheiros do CNE no sentido de regulamentar a construção de projetos pedagógicos relativo aos CSTs, definindo parâmetros curriculares nacionais, assim como procedeu em relação aos cursos técnicos de nível médio, para a educação profissional de nível tecnológico. Conselheiros do Conselho Pleno (CP) do CNE se manifestaram sobre o tema, produzindo o 


\section{Trabalhonecessário}

Issn: $1808-799 X$

ano 11, no $16-2013$

Parecer $\mathrm{CNE} / \mathrm{CP} \mathrm{n}^{0} 29$ sem apresentar a sua concepção sobre educação tecnológica, limitando-se a uma postura argumentativa sobre metas a serem atingidas decorrentes da interpretação das Leis ${ }^{0 s}$ 9.394/1996 e 10.172/2001, tendo como elemento norteador os pressupostos do Decreto $n^{0} 2.208 / 1997$, configurando-se como a oferta de uma educação de nível superior diferenciada que corresponde à própria educação profissional. Verifica-se no Parecer CNE/CP $n^{0}$ 29/2001 que conselheiros enaltecem os CSTs, a institucionalidade CEFET, potencializam a estrutura curricular dos tecnólogos, considerando seus princípios, todavia, os remetem ao deleite da iniciativa privada $^{12}$, por não ser possível equalizar toda essa retórica argumentativa com as limitações de carga horária que já haviam sido anteriormente definidas por eles mesmos, mantendo-os como cursos de curta duração e como demandas dos segmentos produtivos.

A educação profissional de nível tecnológico em 2006, já no governo de Lula, passa por um novo processo de reestruturação a partir da iniciativa do MEC junto ao CNE, decorrente do Parecer CNE/CES $n^{0} 277$, fundamentado em questões que, no entendimento de conselheiros, revolucionaram o desenvolvimento científico e impactam no desenvolvimento tecnológico. Assim sendo, haveria a necessidade de uma reorganização dos CSTs por poucos eixos tecnológicos e mais compactos, face à organização por áreas profissionais definidas no Parecer CES/CNE $n^{0}$ 436/2001 encontrar-se superada e não contribuir para o desenvolvimento industrial. No Parecer CNE/CES $n^{\circ}$ 277/2006 conselheiros mantêm as tradicionais cargas horárias dos CSTs, reforçam a importância da flexibilidade como sendo uma necessidade a ser conseguida a partir da interdisciplinaridade, sem, contudo, abordar esta questão que é apropriada para propiciar mobilidade.

${ }^{12}$ Esta discussão está posta na tese de Azevedo (2011): "De CEFET a IFET. Cursos superiores de tecnologia no Centro Federal de Educação Tecnológica de Santa Catarina: gênese de uma nova institucionalidade?".

TrabalhoNecessário - www.uff.br/trabalhonecessario; Ano 11, № 16/2013. 


\section{Trabalhonecessário}

Issn: $1808-799 X$

ano 11, no $16-2013$

Transparece na manifestação de conselheiros do CNE sobre a educação profissional que a interdisciplinaridade ou transdisciplinaridade desponta como uma estratégia pedagógica para viabilizar um determinado fim, com cuja compreensão não se concorda. Esses, todavia, esquivam-se de abordar uma determinada tendência teórica que daria guarida a sua visão de educação profissional, inclusive sobre possíveis orientações teóricas que possibilitassem aos professores avaliar sua prática de sala de aula, limitando-se a apontar destinos. Entende-se que a questão referida é de importância para a realização do trabalho educativo desenvolvido pelos professores porque Ihes permitem apreender a relação pedagógica para além do desenvolvimento de um processo educacional centrado no aluno ou apenas no professor, pois, no entendimento de Luckesi (1990, p. 74), no transcorrer desse processo "há um confronto do aluno entre sua cultura e a herança cultural da humanidade, entre seu modo de viver e os modelos sociais desejáveis para um projeto de sociedade".

Qual seria, portanto, o projeto de sociedade a que conselheiros do CNE se referenciam para propor toda uma série de regulamentações para a educação profissional? Qual seria a concepção pedagógica que possibilitaria desenvolver para com esse projeto societário?

De uma forma geral o que está posto é que a educação institucionalizada, conforme discute Mészáros (2008, p. 35), "nos últimos 150 anos, serviu - no seu todo - ao propósito de não só fornecer os conhecimentos e o pessoal necessário à máquina produtiva em expansão do sistema capital", assim como manteve segmentos da sociedade num contexto de conformismo como se não houvesse alternativa à construção de outra sociedade que não fosse a dominação de uma maioria por uma minoria, que impõe uma subordinação existencial para o deleite dos benefícios produzidos. 


\section{Trabalhonecessário}

Issn: $1808-799 X$

ano $11, \mathrm{n}=16-2013$

\section{O ENCANTO QUE DESENCANTA A EDUCAÇÃO PROFISSIONAL}

Verifica-se na manifestação de conselheiros do CNE pela via normativa que é desencadeada a partir do MEC a persistência da venda do encantamento de uma condição de empregabilidade para os jovens da sociedade brasileira a partir da educação profissional de forma a aliviar o tradicional ensino superior público das constantes reivindicações de segmentos da base da sociedade ${ }^{13} \mathrm{e}$ possibilitar a formação de uma força de trabalho de reserva o mais numerosa possível, contribuindo, desta forma, para o desenvolvimento econômico e social do Estado brasileiro capitalista, e aliviando pressões sociais, como a de por cursos de bacharelado. Foi nesse sentido que governos de matizes políticas diversas reformaram e normatizaram a educação profissional que se constitui como um ensino específico, focado e diversificado para atender expectativas diversas, àquelas dos setores produtivos e econômicos, assim como as de cunho social que buscam a conformação e o alívio de tensões na base da sociedade, que na contemporaneidade passam a ser rotuladas como inclusão ${ }^{14}$, com o intuito de amenizar a situação de bolsões de miséria e pobreza que tenderiam a abalar estruturas sociais vigentes.

\footnotetext{
${ }^{13}$ Fernando Costa (2008), vice-reitor da Universidade Estadual de Campinas (Unicamp), defendendo a "expansão do ensino superior público planejada", comenta que somente " $13 \%$ dos brasileiros entre 18 e 24 anos frequentam o ensino superior", contrapõe este dado com os dos países da Organisation for Economic Co-operation and Development (OCDE), em que a porcentagem média é de $30 \%$ e na Coréia do Sul é de $60 \%$, e que, destes 13\%, no Brasil, somente $9 \%$ concluem o ensino superior.

${ }^{14}$ Sobre a questão da inclusão/exclusão, Sposati (2006, p. 5) compreende que "A banalização do conceito exclusão/ inclusão social vem, em primeiro plano, de seu uso substituto aos conceitos de opressão, dominação, exploração, subordinação entre outros tantos que derivam do exame crítico da luta de classes da sociedade salarial, como mera modernização da definição de pobre, carente, necessitado, oprimido. A relação entre exclusão/inclusão identifica a iniquidade da desigualdade. Confrontar a exclusão na sua relação com a inclusão é colocar a análise no patamar ético-político, como questão de justiça social, possibilitando a descoberta de novas identidades e dinâmicas sociais. Ninguém é plenamente excluído ou permanentemente incluído. Não se trata de uma condição de permanência, mas da identificação da potência do movimento de indignação e inconformismo. A exclusão social é a apartação de uma inclusão pela presença da discriminação e do estigma."
}

TrabalhoNecessário - www.uff.br/trabalhonecessario; Ano 11, № 16/2013. 


\section{Trabalhonecessário}

Issn: $1808-799 X$

ano 11, no $16-2013$

Compreende-se que foi a partir desta perspectiva que o governo Lula agiu ignorando a Rede Federal de Educação Tecnológica e criou uma nova rede denominada por ele de Rede Federal de Educação Profissional, Científica e Tecnológica, assim como reorganizou centenárias instituições de educação profissional e tecnológica num tipo de instituição denominado por este como Instituto Federal de Educação, Ciência e Tecnologia (IFET), compreendendo-a como uma "nova institucionalidade", haja vista que comunidades internas das tradicionais autarquias gestionavam no sentido de desenvolver CEFETs e chegar à condição de Universidade Tecnológica Federal (UTF) ${ }^{15}$, porém com uma concepção de educação definida a partir do ensino fundamental que incorporasse estágios formativos para além da ótica do mercado ou do uso destas dirigido a um serviço a amenizar mazelas sociais.

Essa ação do governo Lula que havia se autointitulado "o governo dos trabalhadores", todavia, a) não superou a condição de uma educação profissional que se traduz como um ensino direcionado unilateralmente para as profissões e marcado pela imposição de ofertas configuradas de acordo com demandas dos segmentos produtivos; b) não possibilitou a estruturação de projetos pedagógicos de cursos técnicos integrados que viesse a superar a condição de cursos justapostos; c) não rompeu com a lógica dos CSTs de curta duração, cujos egressos da área industrial são negados por segmentos da própria estrutura do Estado brasileiro, como o caso da Petrobrás; d) abandonou os egressos de CSTs à selvageria do mercado que se farta de um profissional de qualidade mediante baixa retribuição e valorização; e e) negou aos segmentos marcados pela

\footnotetext{
${ }^{15}$ Avalia-se que esta discussão está posta por Lima Filho (2005, p. 363) em: "A universidade tecnológica e sua relação com o ensino médio e a educação superior", ao compreender que a Universidade Tecnológica para a sociedade brasileira deve ser vista como um conceito em construção. O autor entende que "a adjetivação do termo universidade sempre é uma operação complexa que pode nos conduzir a armadilhas", em face de que o adjetivo tecnológico associado ao termo universidade tende a "atribuir-Ihe uma especialização ou especificidade de campo de saber" e, desta forma, haveria uma negação relacionada à "universalidade e universalização dos saberes".
}

TrabalhoNecessário - www.uff.br/trabalhonecessario; Ano 11, № 16/2013. 


\section{Trabalhonecessário}

Issn: $1808-799 X$

ano $11, \mathrm{n}=16-2013$

pobreza e discriminação social decorrente do capitalismo a possibilidade da constituição de uma Rede de Universidades Tecnológicas Federais, incumbidas de uma prática educacional suportada na modalidade educação tecnológica.

Ao se fazer um recorte histórico verifica-se que a partir de 1994 o governo Itamar instituiu o Sistema Nacional de Educação Tecnológica e transformou potencialmente todas as Escolas Técnicas Federais (ETFs) da época em CEFETs, mediante a Lei $n^{0}$ 8.948; em 1996 o governo FHC publicou a Lei $n^{\circ}$ 9.394, a "Lei de Diretrizes e Bases da Educação Nacional", a qual apresenta um capítulo específico sobre a educação profissional constituído pelos artigos 39 a 42 que nada dizem, ou seja, caso não existissem não fariam a menor falta; logo em seguida o governo FHC publicou o Decreto $n^{\circ}$ 2.208/1997 com vistas a regulamentar o parágrafo segundo do artigo 36 e os artigos 39 a 42, tudo segundo uma visão de governo, de partido político, e aquém do debate anteriormente instalado no Congresso Nacional, acomodando interesses específicos de forças da sociedade, como a de instituições educacionais privadas e dos segmentos produtivos e econômicos. Considera-se necessário para o propósito do texto destacar que o governo $\mathrm{FHC}$, na descontinuidade governamental, dá continuidade ao projeto do governo Itamar para a expansão da Rede Federal de Educação Tecnológica que tinha por objetivo central a formação de tecnólogos, mesmo revogando o Sistema Nacional de Educação Tecnológica.

No ano de 2004 o governo Lula publica o Decreto $n^{0} 5.154$ também com o propósito de regulamentar o parágrafo segundo do artigo 36 e os artigos 39 a 42 , revogando o Decreto $n^{\circ} 2.208 / 1997$ do governo $\mathrm{FHC}$ que, de uma forma geral, não revogou, apenas reescreve-o nas mesmas bases ideológicas. Verifica-se que o governo Lula, independente do viés político que foi forjada a Lei $n^{\circ} 9.394 / 1996$, também se julgou no direito de regulamentar o que não havia sido instituído pelo seu governo, caracterizando uma continuidade, e ainda sem consultar a sociedade brasileira, caracterizando um completo descaso, apesar de 


\section{Trabalhonecessário}

Issn: $1808-799 X$

ano $11, \mathrm{n}=16-2013$

autointitular-se o governo dos trabalhadores. Sobre a questão do Decreto $\mathrm{n}^{\circ}$ 5.154/2004, Frigotto, Ciavatta e Ramos (2005) fazem referência a um compromisso que o governo Lula tinha assumido com os educadores progressistas em relação à revogação do Decreto $n^{0} 2.208 / 1997$, mediante uma nova lei e não decreto revogando decreto. Percebe-se na manifestação desses autores uma decepção porque a questão era e continua sendo de uma amplitude maior, por não se tratar de imprimir apenas uma nova norma legal e porque, para transcender o contexto, se fazia necessário forjar um novo projeto societário com - coletivo da sociedade e não com a sua representação, mascarando intencionalidades.

Na compreensão de Frigotto, Ciavatta e Ramos (2005), referindo-se a uma educação politécnica com vistas a transpor o modelo de educação profissional vigente, esta poderia superar uma educação com fim em si mesmo, assim como não se pautaria segundo interesses do mercado, por direcionar-se a uma formação ampla e integral de forma a transpor o seu caráter assistencialista. Os autores esperavam que o governo Lula propusesse medidas na premissa de resgatar o desmonte educacional produzido na década de 1990, em contrapartida publicou a Lei $\mathrm{n}^{0}$ 11.892/2008 (Não está nas referências) conformando as tradicionais autarquias federais de educação tecnológica e manteve o status quo da educação profissional normatizada por conselheiros do CNE, na mesma lógica do governo FHC que, mesmo sendo um governo de descontinuidade que criticou posturas políticas de seu antecessor, reproduziu, do ponto de vista da educação profissional, o que estava instituído, recrudescendo-o.

O referencial discursivo do governo Lula que deu sustentação na conformação de autarquias federais de educação tecnológica em IFETs sustentase, no entendimento de Pacheco e Rezende (2009), na promoção da justiça social, na busca da equidade, na viabilização de um desenvolvimento sustentável, promovendo a inclusão social, tudo isso numa concepção construtiva de 


\section{Trabalhonecessário}

Issn: $1808-799 X$

ano $11, \mathrm{n}=16-2013$

sociedade em que o fator predominante continua sendo a busca da "mais-valia", que na contemporaneidade está subjacente na cantilena da necessidade de uma inovação geométrica e a qualquer preço porque é preciso inovar constantemente para se conseguir chegar a outra condição de desenvolvimento que, a princípio, materializa-se na questão monetária e na propriedade privada, aprofunda a exploração humana e acentua a exclusão. Esses autores deixam patente o tipo de compromisso que os IFETs devem ter com os arranjos produtivos de forma a providenciar a formação da força de trabalho necessária e de acordo com a agilidade requisitada, inclusive em conformidade com 0 arcabouço de conhecimentos técnicos e tecnológicos vigentes.

$\mathrm{Na}$ ação do governo Lula com os IFETs, verifica-se que este também contribuiu para aprofundar a privatização da educação profissional, induzindo-a a render-se unilateralmente aos anseios do mercado de forma a reproduzir o ilusionismo de uma empregabilidade aligeirada a partir de uma perspectiva educacional que estava e continua em curso, bem como negou uma "educação dimensionada dentro dos determinantes sociais" (LUCKESI, 1990, p. 49) e conduziu a partir de uma condição autoritária, porque foi construída em gabinete e pelas costas de comunidades internas das autarquias ${ }^{16}$ que se movimentavam no sentido de desenvolver suas práticas educacionais, assim como a concepção de instituição que Ihes davam sustentação. $O$ trabalho educativo, portanto, se constitui como uma produção social e a partir da construção de relações sociais, as quais não estão dadas, e necessitam, para sua efetivação, que os professores dominem "instrumentos de elaboração e sistematização" (SAVIANI, 1999, p. 91), de forma a superar uma concepção puramente tecnicista, por não possibilitar a apreensão do conhecimento para além do seu uso em forma de mercadoria e, ainda, manter o saber privatizado.

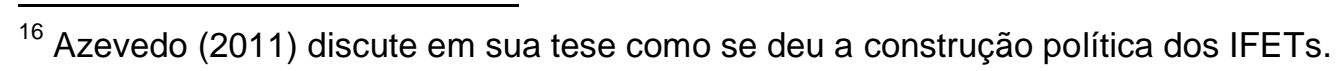

TrabalhoNecessário - www.uff.br/trabalhonecessario; Ano 11, № 16/2013. 


\section{Trabalhonecessário}

Issn: $1808-799 X$

ano 11, no $16-2013$

O resultado é que, de acordo com as condições atuais de contorno de segmentos produtivos, decorrente de uma apropriação crescente por ciência e tecnologia, desponta a necessidade de desenvolver a crescente intelectualização da formação da força de trabalho, devido ao grau de complexidade e dinamicidade que os sistemas econômicos e produtivos passam a incorporar, fazendo do conhecimento um instrumento para galgar novos patamares de desenvolvimento social e não puramente mercantil. Avalia-se que essa pressão pelo domínio da tecnologia não está direcionada apenas para processos fabris, mas se espraia por todos os segmentos societários por ação do poder midiático que, sob uma lógica pensada, induz determinados segmentos sociais a questionarem e se rebelarem contra uma possível exclusão associada à sua capacidade de consumo, voltando-se contra o Estado capitalista que responde, reciclando o vigente, porém continua a negar a "universalização conjunta do trabalho e da educação" (MÉSZÁROS, 2008, p. 67).

Dito isso, é pertinente refletir sobre a falsa ilusão de que 0 desenvolvimento da ferramenta, da máquina e do autômato, como resultado de um trabalho humano histórico que se realimenta do anterior e contribui para se chegar a um novo resultado, viria a desonerar a sua imersão nesse contexto. Entende-se que esta premissa não se consolida, já que quanto mais o ser humano se estranha com a Natureza e com outras formas de natureza produzidas por ele mesmo, a vivência se torna mais complexa e necessita, para a sua manutenção, a formação da força de trabalho com maior potencial de intelectualidade e de densidade epistemológica, no que tange ao desenvolvimento de capacidades.

Os IFETs, todavia, não foram pensados a partir da superação de uma apropriação educacional entendida como educação profissional e tecnológica com vistas à formação do ser humano para a vida, edificada sobre os princípios da politecnia com vistas a construção da emancipação humana do jugo do capital, 


\section{Trabalhonecessário}

Issn: $1808-799 X$

ano 11, no $16-2013$

mas sim para a manutenção de uma condição de vida mediada pela lógica do capital. Para dar consistência a esta reflexão, destaca-se que na "Chamada Pública MEC/SETEC n 002/2007" o governo Lula explicita que essa "nova institucionalidade" tem por objetivo o "acolhimento de um público historicamente colocado à margem das políticas de formação para o trabalho, a pesquisa aplicada destinada à elevação do potencial das atividades produtivas locais e a democratização do conhecimento à comunidade em todas as suas representações", a partir da qual é possível abstrair o seu propósito produtivo, face aos vínculos estabelecidos, de forma a manter o existente segundo a mesma perspectiva histórica, agora de "pobres e desvalidos da sorte" (RUMMERT, 2005) para "desfavorecidos do consumismo", materializando dessa forma o que dissemos no título: para os "pobres e desvalidos da sorte" uma educação escassa para que possam tentar se incluir na perversa sociedade de classes sob os ditames do capital. 


\section{Trabalhonecessário}

Issn: $1808-799 X$

ano $11, \mathrm{n}=16-2013$

\section{REFERÊNCIAS:}

AZEVEDO, Luiz Alberto. De CEFET a IFET. Cursos Superiores de Tecnologia no Centro Federal de Educação Tecnológica de Santa Catarina: gênese de uma nova institucionalidade? 2011. 192 f. Tese (Doutorado em Educação). Programa de Pós-Graduação em Educação. Universidade Federal de Santa Catarina, Florianópolis, 2011.

BRASIL. Congresso Nacional. Comissão Parlamentar Conjunta do MERCOSUL. Decreto Legislativo $n^{0}$ 800/2003. Acordo de admissão de títulos e graus universitários para o exercício de atividades acadêmicas nos estados partes do MERCOSUL. (mimeo).

. Instituto Brasileiro de Geografia e Estatística. Brasil já tem mais de 180 milhões de habitantes. Disponível em: $<$ http://www.ibge.gov.br/home/presidencia/noticias/noticia visualiza.php?id noticia $=207>$. Acesso em: 2 abr. 2012.

. Ministério da Educação. Parecer CEB/CNE n 5, de 7 de maio de 1997 a. Proposta de Regulamentação da Lei $n^{\circ}$ 9.394/1996. Relator Conselheiro Ulysses de Oliveira Panisset. Brasília: MEC, 1997. 11p. Disponível em: <http://portal.mec.gov.br/cne/arquivos/pdf/1997/pceb005_97.pdf>. Acesso em: Acesso em: 20 mar. 2012.

. Ministério da Educação. Parecer CEB/CNE n ${ }^{\circ} 17$, de 3 de dezembro de 1997 b. Diretrizes operacionais para a educação profissional de em nível nacional. Relator Conselheiro Fábio Luiz Marinho Aidar. Brasília: MEC, 1997. 7p. Disponível em: <http://portal.mec.gov.br/cne/arquivos/pdf/1997/pceb017_97.pdf>. Acesso em: Acesso em: 20 mar. 2012.

. Ministério da Educação. Parecer CEB/CNE $n^{\circ} 16$, de 5 de outubro de 1999. Diretrizes curriculares nacionais para a educação profissional de nível médio. Relator Conselheiro Francisco Aparecido Cordão. Brasília: MEC, 1999. 


\section{Trabalhonecessário}

Issn: 1808 - 799X

ano $11, \mathrm{n}=16-2013$

$88 p$.

Disponível

em:

<http://portal.mec.gov.br/cne/arquivos/pdf/1999/pceb016_99.pdf>. Acesso em: 20 mar. 2012.

. Ministério da Educação. Parecer CES/CNE n 436, de 2 de abril de 2001.

Cursos Superiores de Tecnologia - Formação de Tecnólogos. Relator Conselheiro Carlos Alberto Serpa de Oliveira. Brasília: MEC, 2001. 23p. Disponível em: <http://portal.mec.gov.br/index.php?option=com_content\&view=article\&id=13243 \%3Aparecer-ces-2001\&catid=323\%3Aorgaos-vinculados\&ltemid=866>. Acesso em: 20 mar. 2012.

- Ministério da Educação. Parecer CP/CNE n ${ }^{\circ} 29$, de 3 de dezembro de 2002. Diretrizes Curriculares Nacionais Gerais para a Educação Profissional de Nível Tecnológico. Relator Conselheiro Francisco Aparecido Cordão. Brasília: MEC, 2002. 44p. Disponível em: <http://portal.mec.gov.br/cne/arquivos/pdf/cp29.pdf>. Acesso em: 20 mar. 2012. . Ministério da Educação. Parecer $\mathrm{CEB} / \mathrm{CNE} \mathrm{n}^{\circ} 39$, de 8 de dezembro de 2004. Aplicação do Decreto no 5.154/2004 na Educação Profissional Técnica de nível médio e no Ensino Médio. Relator Conselheiro Francisco Aparecido Cordão. Brasília: MEC, $2004.212 p . \quad$ Disponível em: $<$ http://portal.mec.gov.br/cne/arquivos/pdf/ceb39.pdf>. Acesso em: 20 mar. 2012. . Ministério da Educação. Parecer CES/CNE n 277, de 7 de dezembro de 2006. Nova forma de organização da Educação Profissional e Tecnológica de graduação. Relator Conselheiro Luiz Bevilacqua. Brasília: MEC, 2006. 9p. Disponível em: <http://portal.mec.gov.br/setec/arquivos/pdf/pces277 06.pdf $>$. Acesso em: 20 mar. 2012.

- Ministério da Educação. Programa Nacional de Acesso ao Ensino Técnico Emprego. Disponível em: $<$ http://pronatecportal.mec.gov.br/pronatec.html>. Acesso em: 7 abr. 2012. 


\section{Trabalhonecessário}

Issn: $1808-799 X$

ano 11, no $16-2013$

. Ministério da Educação e do Desporto. Balanço das realizações do MEC no $1^{\circ}$ trimestre do ano de 1993. Brasília, abril de 1993. 67p. (mímeo).

. Senado Federal. Decreto $\mathrm{n}^{0} 2.208$, de 17 de abril de 1997. Regulamenta o § $2^{\circ}$ do art. 36 e os arts. 39 a 42 da Lei $n^{\circ}$ 9.394, de 20 de dezembro de 1996, que estabelece as diretrizes e bases da educação nacional. Disponível em: $<$ http://www6.senado.gov.br/legislacao/ListaPublicacoes.action?id=146021\&tipoD ocumento=DEC\&tipoTexto=PUB $>$. Acesso em: 20 mar. 2012.

. Senado Federal. Decreto $n^{0} 5.154$, de 23 de julho de 2004. Regulamenta o $\S 2^{\circ}$ do art. 36 e os arts. 39 a 41 da Lei no 9.394, de 20 de dezembro de 1996, que estabelece as diretrizes e bases da educação nacional, e dá outras providências.

Disponível

em:

$<$ http://www6.senado.gov.br/legislacao/ListaPublicacoes.action?id=238991\&tipoD ocumento=DEC\&tipoTexto=PUB $>$. Acesso em: 20 mar. 2012.

. Senado Federal. Lei $n^{\circ} 8.948$, de 8 de dezembro de 1994. Dispõe sobre a instituição do Sistema Nacional de Educação e dá outras providências. Disponível em:

$<$ http://www6.senado.gov.br/legislacao/ListaPublicacoes.action?id=140342\&tipoD ocumento=LEl\&tipoTexto=PUB $>$. Acesso em: 3 abr. 2012.

. Senado Federal. Lei $n^{0} 9.131$, de 24 de novembro de 1995. Altera dispositivos da Lei no 4.024, de 20 de dezembro de 1961, e dá outras providências.

Disponível

em:

$<$ http://www6.senado.gov.br/legislacao/ListaPublicacoes.action?id=142301\&tipoD ocumento=LEl\&tipoTexto=PUB $>$. Acesso em: 3 abr. 2012.

. Senado Federal. Lei $n^{0}$ 9.394, de 20 de dezembro de 1996. Estabelece as diretrizes e bases da educação nacional. Disponível em: $<$ http://www6.senado.gov.br/legislacao/ListaPublicacoes.action?id=102480\&tipoD ocumento=LEl\&tipoTexto=PUB $>$. Acesso em: 2 abr. 2012. 


\section{Trabalhonecessário}

Issn: $1808-799 X$

ano 11, no $16-2013$

COSTA, Fernando. Pela expansão do ensino superior público. Folha de São Paulo, Tendências/Debates, 28/3/2008. Disponível em: $<$ http://www.unicamp.br/unicamp/divulgacao/2008/03/28/fernando-costa-defendeexpansao-planejada>. Acesso em: 9 abr. 2012.

CUNHA, Luiz Antônio. O ensino de ofícios artesanais e manufatureiros no Brasil escravocrata. 2. ed. São Paulo: UNESP; Brasília: FLACSO, 2005. 190p.

. O ensino de ofícios nos primórdios da industrialização. São Paulo: UNESP; Brasília: FLACSO, 2000. 243p.

. O ensino de ofícios na irradiação do industrialismo. São Paulo: UNESP; Brasília: FLACSO, 2000. 270p.

DEPARTAMENTO INTERSINDICAL DE ESTATÍSTICA E ESTUDOS SOCIOECONÔMICOS. Desindustrialização: conceito e a situação do Brasil, 2011. (mimeo).

FRIGOTTO, Gaudêncio; CIAVATTA, Maria; RAMOS, Marise. A gênese do Decreto $n^{\circ}$ 5.154/2004: um debate contexto controverso da democracia restrita. Trabalho necessário, ano 3, n. 3, 2005. Disponível: $<$ http://www.uff.br/trabalhonecessario/MMGTN3.htm>. Acesso em: 15 jul. 2010. KUENZER, Acácia Zeneida. A educação profissional nos anos 2000: a dimensão subordinada das políticas de inclusão. Educação \& Sociedade, v. 27, n. 96 Especial, p. 877-910, out. 2006. Disponível em: <http://www.scielo.br/pdf/es/v27n96/a12v2796.pdf>. Acesso em: 2 abr. 2012.

LIMA FILHO, Domingos Leite. A universidade tecnológica e sua relação com o ensino médio e a educação superior: discutindo a identidade e o futuro dos CEFETs. Perspectiva, Florianópolis, v. 23, n. 2, p. 349-380, jul./dez. 2005. (mimeo).

LUCKESI, Cipriano Carlos. Filosofia da educação. São Paulo: Cortez, 1990. 183p. 


\section{Trabalhonecessário}

Issn: $1808-799 X$

ano 11, no $16-2013$

MARX, Karl. O Capital: crítica da economia política: livro 1, 2 v., 26. ed. Tradução de Reginaldo Sant'Anna. Rio de Janeiro: Civilização Brasileira, 2008. p. 966. Na citação estava 2005. verificar

MÉSZÁROS, Isván. A educação para além do capital. Tradução de Isa Tavares. 2. ed. São Paulo: Boitempo, 2008. 124p.

NOSELLA, Paolo. Compromisso político e competência técnica: 20 anos depois. Educ. Soc., Campinas, vol. 26, n. 90, p. 223-238, Jan./Abr. 2005. Disponível em: <http://www.scielo.br/pdf/es/v26n90/a10v2690.pdf>. Acesso em: 10 abr. 2012.

PACHECO, Eliezer; REZENDE, Caetana. Institutos Federais um futuro por amar, p. 7-11. In: Institutos Federais lei 11.892, de 29/11/2008: comentários e reflexões. Organização de Caetana Juracy Rezende Silva. Natal: IFRN, 2009. 70p. (mímeo) RAMOS, Marise Nogueira Ramos. A educação profissional pela pedagogia das competências e a superfície dos documentos oficiais. Educação \& Sociedade, v. 23, n. 80, set. 2002, p. 401-422. (mimeo).

RUMMERT, Sonia Maria. Projeto escola de fábrica - atendendo a "pobres e desvalidos da sorte" do século XXI. Revista Perspectiva, Vol. 23, n. 5. Florianópolis, Santa Catarina, Brasil. 2005.

SAVIANI, Dermeval. Pedagogia histórico-crítica: primeiras aproximações. 6. ed. São Paulo: Autores Associados, 1997. 128p.

. Trabalho e educação: fundamentos ontológicos e históricos. Revista Brasileira de Educação, v. 12, n. 34, jan./abr. 2007, p. 152-180. Disponível em: $<$ http://www.scielo.br/pdf/rbedu/v12n34/a12v1234.pdf >. Acesso em: 12 mar. 2012. SPOSATI, Aldaíza. A fluidez da inclusão/exclusão social. Ciência e Cultura, São Paulo, v. 58, n. 4, out./dez. 2006. Disponível em: $<$ http://cienciaecultura.bvs.br/scielo.php?pid=S0009-

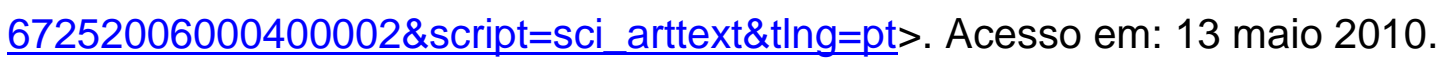




\section{Trabalhonecessário}

Issn: 1808 - 799X ano 11, no $16-2013$

VIEIRA PINTO, Álvaro. O conceito de tecnologia. v. I. Rio de Janeiro: Contraponto, 2005. 531p.

Data de recebimento: 11/03/2013

Data de aprovação: 16/04/2013 